\title{
Building Regional Entrepreneurial Ecosystem for High-level Talents: Evidence from China*
}

\author{
Xin Li \\ Xi'an Jiaotong University City College \\ Xi'an, China 710018 \\ School of Public Policy and Administration \\ Xi'an Jiaotong University \\ Xi'an, China 710048
}

\begin{abstract}
It is widely acknowledged that entrepreneurial activities can be propelled by the high-level talents, which is dependent of the key elements in the whole entrepreneurial eco-system and also driven by economic and social development in the region. The worldwide competitions for the talents have been increasingly fierce in term of both upgrading of the globalization and improving of the technology. Within the theoretical framework of entrepreneurial eco-system, the study uses the data from the Recruitment Program of Global Experts in Shaanxi Province and Sichuan Province, and then analyzes empirically the channel of recruitment, research team formation, research platform building, and the interaction between research and industry. The findings can inform research on the incentive and management mechanism of highlevel talents, and advice for the entrepreneurial eco-system building in certain regions is discussed.
\end{abstract}

Keywords-entrepreneurship ecosystem; regional development; talent

\section{INTRODUCTION}

High-tech entrepreneurship has many benefits. For individuals, it can realize their self-value, pursuit of wealth, and expand their social and interpersonal circle. For the whole society, entrepreneurship is the main lasting power to promote economic development [1]. A lot of new technologies, services and business models are realized and promoted to the mass consumers through the initiation of new enterprises. In recent years, scholars of entrepreneurship and firm strategy research have widely applied the conceptual framework of entrepreneurial ecosystems as a theoretical analysis tool, to examine how to promote the growth and development of entrepreneurial ecosystems in different geographical regions.

The concept of ecosystem in natural science (including the complex relationship between the biological community and the elements of the physical environment associated with it) has been extended by scholars to the burgeoning analysis of entrepreneurial phenomena. Entrepreneurial ecosystem

*Fund: This work is funded by the Scientific Research Project of Education Department of Shaanxi Provincial Government under Grant 17JK1007 and the Scientific Project Program of Xi'an Jiaotong University City College (Project Number: 2016KR06). refers to the combination of the relationship between entrepreneurial community elements and local cultural perspectives, social networks, investment venture capitals, universities, economic policies and other characteristic features in all entrepreneurship and innovation activities [2]. Researchers study various environmental traits and elements supporting entrepreneurial activities in a certain region. Compared with the extension and construction of theories, empirical studies on how to form such a sustainable community and the interdependence and commonness among various characteristics and elements within the entrepreneurial ecosystem in practice and policy formulation are less involved, which is the key to the creation and promotion of entrepreneurship-friendly ecosystem.

Based on this situation, this study analyzes the composition, hierarchy and interaction of elements of the entrepreneurial ecosystem from an empirical perspective. Based on the entrepreneurship and innovation status of highlevel talents in Shaanxi province in recent years, it compares and analyzes the internal characteristics and governance strategies of the entrepreneurial ecosystem of high-level talents in Sichuan province. On the basis of summarizing the successful experience, this paper provides reference and suggestions for the establishment of an entrepreneurshipfriendly policy environment in Shaanxi province, so as to catch up with and surpass the technological and talent potential. Next, the second part summarizes the research progress of extant theories in entrepreneurial ecosystem, characteristics and aggregation effect of high-level talents, institutional environment and regional innovation system. It defines the characteristics of the entrepreneurial ecosystem at three different levels: cultural, social and material. Then the third part is the comparative analysis of 2015-2017 within three years, represented by the national "One Thousand Project" of high-level talents in Shaanxi and Sichuan provinces of demographic characteristics, talent distribution, local support policy and knowledge spillover effect of human resource management and the characteristics of the knowledge driven economic indicators. The detailed empirical analysis shows that the entrepreneurship-friendly ecosystem environment is the accumulation of the positive interaction between the above characteristic elements, forming the supporting environment of the region to promote 
the competitiveness of new enterprises, which cannot be measured by the high entrepreneurship rate alone. Moreover, the characteristic elements on three levels of entrepreneurial ecosystem can have different configuration. Finally, the research conclusions are drawn and discussed, which can be applied to the knowledge management of high-level talents and building of regional entrepreneurship system.

\section{LITERATURE REVIEW}

\section{A. Characteristics of High-level Talents}

Talents refer to those who have certain professional knowledge or expertise, engaging in creative labor and make contributions to the society; or workers with higher ability and quality in human resources [3]. In April 2010, China issued the first medium - and long-term talent development plan, namely the outline of national medium - and longterm talent development plan (2010-2020) (hereinafter referred to as the outline of talent development plan), which constitutes a guiding document for national talent development in the future. It is well-established that talents are the first resource for China's economic and social development [4]. According to the statistical data of the six categories of high-level talents selected in 31 provinces of the Chinese mainland from 2013 to 2017, all the top 10 provinces are developed in the east except Hubei, Shaanxi and Sichuan, while the bottom 10 provinces are all central and western provinces. The number of high-level talents selected in some provinces in the past five years is 0 .

Generally speaking, these high-level talents are generally applied by professors and doctoral supervisors in China's top universities, and academicians of the Chinese Academy of Sciences. The top 10 provinces are all regions with abundant higher education resources and scientific research institutes. Outside the top three cities of Beijing, Shanghai and Jiangsu, the provinces of Guangdong and Hubei have improved faster, especially Sun Yat-sen University, Wuhan University and Huazhong University of Science and Technology. In 2017, 30 people were selected by the national "thousand talents plan" of Sun Yat-sen University, accounting for $12.5 \%$ of the national total. In Tianjin, Shaanxi and Heilongjiang, where higher education has been strong in history, the progress rate of top universities slowed down under the competition of talent strategy of economically strong provinces. This statistical data basically shows the strength of higher education in different regions of China and the huge gap between provinces in terms of high-end scientific research talents.

\section{B. Institutional Environment and Entrepreneurial Ecosystem}

The concept of entrepreneurial ecological environment is borrowed from the ecological system of ecology. Scholar Wang Mingjie (2016) believes that entrepreneurial ecological system is a description of the development status of closely combined innovation and entrepreneurship, economy and society. In recent years, foreign scholars focus on analyzing the new generation of business incubators - accelerator, introducing various incubation mechanisms for policy makers, private investors, companies, universities and research institutions to support and promote the successful establishment of new enterprises. Undoubtedly, in general, the incubation mechanism promotes the emergence of new enterprises, but the heterogeneity of different incubation modes should also be taken into account. In the last five years, a seed accelerator was developed in Europe. The program provided intensive and specialized incubation services within a certain period of time, focusing on education and mentoring. For example, Y Combinator (the first accelerator) was launched in Cambridge, Massachusetts in 2005, and has since been imitated by many accelerators. In 2009, the Different Engine became the first accelerator in Europe. Accordingly, there are 213 accelerators worldwide, supporting about 3,800 startups (Pauwels, Clarysse and Wright et al., 2015).

The system can reduce the transaction cost and uncertainty, and reduce the coordination among economic subjects. The quality indicators of the system include (1) the process of the government being elected, monitored and replaced; (2) the government's ability to effectively formulate and implement sound policies; (3) economic and social interactions between governed citizens and the state. Most scholars generally believe that the institutional environment can promote entrepreneurial opportunities and also restrain entrepreneurs, thus influencing the speed and scale of new enterprises. These institutional factors can influence the efforts of entrepreneurs, including the government to build and maintain an environment supporting entrepreneurship and social norms affirming entrepreneurship. Specifically, the entrepreneurial activity formed by the society is directly related to the rules, regulations and policies for the distribution of rewards in the society [5].

Because the entrepreneurial ecosystem is a potential factor in the whole economic system, it is suggested to use the comprehensive measurement method combined with a number of indicators of the system information, to provide a better solution for measuring the quality of the system. The analysis of entrepreneurial phenomena by institutional economics and the conceptual analysis framework of Spigel's entrepreneurial ecosystem have synergistic effects at three levels (see "Table I" below). 
TABLE I.

ESSENTIAL CHARACTERISTICS OF ENTREPRENEURIAL ECOSYSTEMS

\begin{tabular}{|c|c|}
\hline Level & Features \\
\hline \multirow{2}{*}{ Cultural } & Supportive cultural traits can support and normalize risky and innovative entrepreneurial activities. \\
\hline & Examples of entrepreneurial success in the region are well-known in the history of entrepreneurship. \\
\hline \multirow{4}{*}{ Social } & Workers are skilled who are willing to work in start-ups. \\
\hline & Funding from family friends, angel investors and venture capitalists. \\
\hline & $\begin{array}{l}\text { Social networks that connect entrepreneurs, consultants, investors and skilled workers, in which knowledge and } \\
\text { skills flow freely. }\end{array}$ \\
\hline & $\begin{array}{l}\text { Successful local entrepreneurs and businessmen as mentors and role models can advise young new } \\
\text { entrepreneurs. }\end{array}$ \\
\hline \multirow{5}{*}{ Material } & $\begin{array}{l}\text { Policy and governance programs or regulations at the district level can directly fund entrepreneurship or remove } \\
\text { barriers to the creation of new to support entrepreneurial activity. }\end{array}$ \\
\hline & $\begin{array}{l}\text { Universities and higher education institutions that facilitate knowledge spillovers can train new entrepreneurs as } \\
\text { well. }\end{array}$ \\
\hline & $\begin{array}{l}\text { Support services companies and organizations that provide support services for start-ups such as patent lawyers, } \\
\text { incubators, and accountants. }\end{array}$ \\
\hline & Infrastructure - adequate office space, telecommunications, and transportation enable start-ups to grow. \\
\hline & $\begin{array}{l}\text { Open markets provide ample opportunities for local entrepreneurship and unimpeded access to international } \\
\text { markets. }\end{array}$ \\
\hline
\end{tabular}

${ }^{\text {a. }}$ Adapted from SPIGEL b. The Relational Organization of Entrepreneurial Ecosystems [J]. Entrepreneurship Theory \& Practice, 2015, 41 (1): 49-72.

This model suggests that there can be multiple possible configurations between elements at different levels of the entrepreneurial ecosystem. The existence of multiple overlapping attributes on behalf of the ecosystem encourages entrepreneurial activities and provides key resources. New enterprises can resort to their capabilities in the process of expansion and development (hierarchical relationship is shown in "Fig. 1" below). High-level talents tend to come from overseas universities and research institutes, a high and new technology enterprise of high-level managers or with independent intellectual property rights of invention of science and technology personnel, the enterprise scale is small, they start in the new competitive environment, how to build business friendly ecological environment, from the system level, reduce the transaction costs, improve the innovation performance of policies for policymakers and specification provides empirical research.

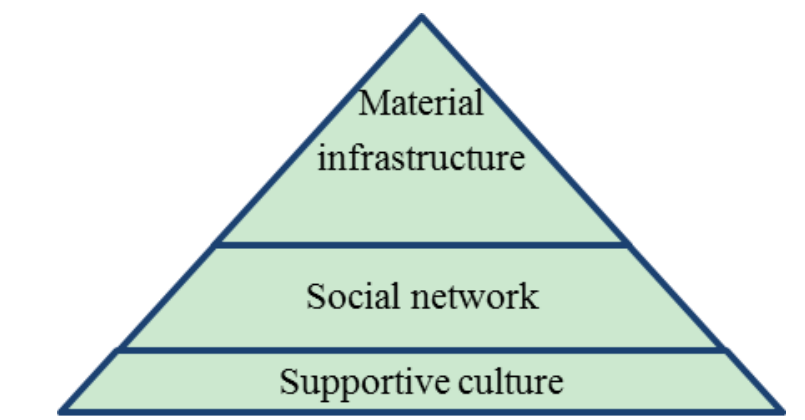

Fig. 1. Relationship between elements and characteristics of entrepreneurial ecosystem.

\section{ANALYSIS OF THE ELEMENTS OF THE ENTREPRENEURSHIP ECOSYSTEM OF HIGH-LEVEL TALENTS IN SHAANXI PROVINCE}

In the new era, China has launched "innovation-driven development" as a national development strategy. The development of science and technology depends on the activities of talents. In order to accelerate the process of China's scientific and technological development, the state has introduced a series of policies to introduce talents. These talents need to overcome various challenges upon their return to China before they can carry out scientific research smoothly. As research becomes increasingly dependent on teams, social networks form as a result of teamwork. These returnees are expected to keep in touch with their old social networks and establish new ones when they return home. There is continuity in research, but the movement of returnees has changed the social network of returnees, and these changes are bound to affect their knowledge creation. Therefore, it is of great significance to study the relationship between the change of social network of high-level talents and knowledge creation.

Shaanxi province, with the advantages in the long-term accumulation of universities and research institutes, goes the way of a powerful province of "talent", which takes the lead across the country in issuing the Shaanxi Province Medium and Long-term Talent Development Plan (2010-2020), in order to build west talent highland. As the overall goal of becoming western province talent, Shaanxi province put forward a number of key engineering talent development strategies. By encouraging and attracting high-level innovative entrepreneurial talents to Shaanxi, The local entrepreneurial ecosystem can improve the comprehensive strength of the talent teams and scientific and technological innovation power in our province. The "Sanqin Scholars" innovation team support plan of Shaanxi province aims to catch up with and surpass the strategic goals of Shaanxi province and implement the "Five New" strategic tasks. It is planned to focus on selecting 300 high-level innovation teams to support in about five years. Take the national program for the introduction of overseas high-level talents ("thousand talents plan") in the past three years from 2015 to 2017 as an example, Shaanxi province is listed in the top ten talent landing provinces

According to data from the Sichuan Provincial Department of Personnel, more than 12,000 foreign experts come to Sichuan for work, exchanges and visits each year, ranking first in the central and western regions and 10th in the country. Summing up the talent strategy of neighboring Sichuan province, it can get the following content. First is to 
reform the work permit system for foreigners in China. Sichuan province took the lead in implementing the reform of the work permit system for foreigners in China, and carried out the pilot integration of "work permit for foreign experts in China" and "employment permit for foreigners in China" (officially implemented in April 2017). Secondly, Sichuan province implements the policy of direct employment of foreign college graduates in Sichuan. Excellent foreign college graduates with master's degree or above are allowed to work in Sichuan. Qualified foreign college graduates can directly work in 21 cities (states) in Sichuan within one year after graduation. Third, the implementation of the talent visa policy for high-end foreign talent identification.

\section{CONCLUSION}

This study clarifies the mechanism between the government and the market in stimulating high-tech firm innovation performance, promoting innovation value chain and the role of entrepreneurial ecosystem formation. The findings can help to define innovative entrepreneurial activities and the role of the market and the government, in that entrepreneurship-friendly environment can set up effective social network and innovation network by disseminating knowledge and increasing trading opportunities. The entrepreneurial ecosystem maximizes the benefits of high-level talents in the field of technology. Useful policy suggestions are provided for institutional innovation. The attributes of an ecosystem are sustainable and replicated through their interactive relationship. In the ecosystem, this duplication is generated by the interaction between entrepreneurs and highly skilled workers in the supportive entrepreneurial culture, effective public programs and organizations. In a sparse ecosystem, one attribute drives others, such as a large local market that creates opportunities for entrepreneurs to take advantage of, grow, and make profit. In theory, the study of entrepreneurial ecosystem should focus not only on the rate of entrepreneurship - but also on inputs such as local culture, social, and material attributes of entrepreneurial activities. The way these attributes interact and reproduce across the ecosystem is critical, too [6]. In practice, this research conclusion can provide policy makers talent introduction policy standards and create conditions for the talent after returning to build social network, but also for young talents and returning scientists' suggestions on how to use social networks to promote knowledge creation. Combined with the comprehensive innovation implementation policy, more open and effective talents introduction policy can positively affect the sustainable development of local entrepreneurial ecosystems, thus boosting economic growth in the long run.

\section{ACKNOWLEDGMENT}

The author should thank Shaanxi Association of Higher Education under Project (XGH17258) China for innumerable data and support.

\section{REFERENCES}

[1] Feist, G.J., A meta - analysis of personality in scientific and artistic creativity [J]. Personality and Social Psychology Review, 1998, 2(4): $290-309$.

[2] Spigel, B., The Relational Organization of Entrepreneuria Ecosystems [J]. Entrepreneurship Theory \& Practice, 2015, 41(1) 49-72.

[3] Wenjie Li, Wenyu Du, Jiamin Yin. Digital Entrepreneurship Ecosystem as a New Form of Organizing: The Case of Zhongguancun [J]. Administrative Tribune. 2016,23(2):99-104

[4] Pauwels, C., Clarysse B, Wright M, et al. Understanding a new generation incubation model: The accelerator [J]. Technovation, 2015 s 50-51:13-24.

[5] Bruton, G. D., Ahlstrom, D. and Li, H.-L. 2010. Institutional Theory and Entrepreneurship: Where Are We Now and Where Do We Need to Move in the Future? Entrepreneurship Theory and Practice, 34: 421-440.

[6] Teece, D. J., Profiting from Technological Innovation: Implications for Integration, Collaboration, Licensing and Public Policy [J]. Research Policy, 2006, 15(6):285-305. 